\title{
Numerical Studies on Natural Convection Heat Losses from Open Cubical Cavities
}

\author{
M. Prakash \\ Department of Energy Science and Engineering, Indian Institute of Technology Bombay, Powai, Mumbai 400076, India \\ Correspondence should be addressed to M. Prakash; prakashmarath@gmail.com
}

Received 10 November 2012; Accepted 4 February 2013

Academic Editor: Mo Yang

Copyright (C) 2013 M. Prakash. This is an open access article distributed under the Creative Commons Attribution License, which permits unrestricted use, distribution, and reproduction in any medium, provided the original work is properly cited.

\begin{abstract}
The natural convection heat losses occurring from cubical open cavities are analysed in this paper. Open cubical cavities of sides $0.1 \mathrm{~m}, 0.2 \mathrm{~m}, 0.25 \mathrm{~m}, 0.5 \mathrm{~m}$, and $1 \mathrm{~m}$ with constant temperature back wall boundary conditions and opening ratio of 1 are studied. The Fluent CFD software is used to analyse the three-dimensional (3D) cavity models. The studies are carried out for cavities with back wall temperatures between $35^{\circ} \mathrm{C}$ and $100^{\circ} \mathrm{C}$. The effect of cavity inclination on the convective loss is analysed for angles of $0^{\circ}$ (cavity facing sideways), $30^{\circ}, 45^{\circ}, 60^{\circ}$, and $90^{\circ}$ (cavity facing vertically downwards). The Rayleigh numbers involved in this study range between $4.5 \times 10^{5}$ and $1.5 \times 10^{9}$. The natural convection loss is found to increase with an increase in back wall temperature. The natural convection loss is observed to decrease with an increase in cavity inclination; the highest convective loss being at $0^{\circ}$ and the lowest at $90^{\circ}$ inclination. This is observed for all cavities analysed here. Nusselt number correlations involving the effect of Rayleigh number and the cavity inclination angle have been developed from the current studies. These correlations can be used for engineering applications such as electronic cooling, low- and medium-temperature solar thermal systems, passive architecture, and also refrigeration systems.
\end{abstract}

\section{Introduction}

Buoyancy-driven heat transfer is one of the most important heat loss mechanisms from open cavities and is now widely studied due to their applications in many engineering fields such as solar thermal conversion, refrigeration, passive architecture, fire research, and electronic equipment cooling. The heat loss due to natural convection from open cavities is dependent on various factors such as shape of cavity, cavity wall boundary conditions, cavity inclination, aspect ratio, and opening ratio. Therefore in open cavities, the natural convection heat transfer analysis is complicated when compared to the heat transfer due to radiation and conduction.

It is observed from the literature that experimental and numerical studies on natural convection in open cavities have been performed for different cavity shapes, namely, cubical [1-6], rectangular [7-17], and square [18-24]. Studies have also been reported on other cavity shapes used for specific applications like solar thermal receivers [25-31].

In the studies involving open cavity natural convection, two basic boundary wall conditions are observed: (a) all the walls of the open cavity were heat transfer surfaces at constant temperature $[1,2,4,6,8,9,12,18,19,21,22,25,26,30-32]$, henceforth referred to as isothermal wall boundary condition and (b) only one wall (wall opposite to the aperture) was at constant temperature and the remaining walls were kept adiabatic, henceforth referred to as constant temperature back wall boundary condition $[3,5,10,11,13,20,23,24,33]$. Other wall boundary conditions such as one wall having constant heat flux and other walls being adiabatic [14-16] and nonisothermal wall temperatures [7, 27-29] were also studied. Chakroun [17] studied the effect of different wall boundary conditions on the natural convection heat transfer from an open cavity.

It is noticed from the literature that there are studies related to natural convection loss from cavities at $0^{\circ}$ (sideways facing cavity) inclination $[2-4,11-14,20,23]$. The effects of more than one angle of cavity inclination (upward and downward facing) on the convective losses are also analysed $[1,5-9,14-19,21,22,24-33]$, and it is inferred from these studies that for a downward facing cavity, the convective loss decreases with an increase in inclination; the highest 
loss being at $0^{\circ}$ inclination and the least at $90^{\circ}$ (vertically downward facing cavity).

The ratio of cavity aperture dimension to the cavity dimension can be termed as opening ratio $(a / H$ or $d / D)$. Opening ratios of $1[1-3,5,6,9-13,16-23,25,26], 0.5[3,8,22$, 30], 0.6 and 0.4 [7], and 0.25 [30] have been studied. Clausing et al. [4], Chakroun et al. [14], Elsayed and Chakroun [15], Bilgen and Oztop [24], Stine and McDonald [28], McDonald [29], and Sendhil Kumar and Reddy [31] have analysed different opening ratios ranging from 1 to about 0.1 . The effect of this ratio on the convection loss is found to be significant as the loss decreased with a decrease in the opening ratio.

It can be observed from the literature that the determination of convective losses from cubical and rectangular open cavities are mainly carried out for isothermal wall boundary condition while studies related to the constant temperature back wall boundary condition are limited. The effect of inclination on the convective loss from open cavities with isothermal wall boundary condition is studied extensively, but the inclination effect on convective loss from cavities with a constant temperature back wall boundary condition is limited to a study by Hinojosa et al. [5]. Studies carried out by Bilgen and Oztop [24] mainly involve the upward facing cavity. Mohamad [34] and Polat and Bilgen [35] have also analysed upward facing cavities with constant heat flux back wall boundary condition. These studies $[24,34,35]$ indicate a weak effect of the inclination angle on the convective losses. The effect of inclination on the convective loss needs to be analysed when the open cavity is used for specific applications such as solar thermal conversion systems, passive architecture, and electronic cooling.

It was also observed that most of the studies from cubical and rectangular open cavities with a constant temperature back wall boundary condition are limited to Rayleigh numbers of about $10^{7}$ except for studies such as Hess and Henze [3] and Chan and Tien [10], where Rayleigh numbers of about $10^{11}$ and $10^{9}$ have been analysed, respectively. Nusselt number correlations have been proposed for open cavities with a constant temperature back wall boundary condition, but their use is limited to $0^{\circ}$ inclination and low Rayleigh numbers.

In this communication, numerical studies of natural convection heat transfer from open cubical cavities of sides $0.1 \mathrm{~m}$, $0.2 \mathrm{~m}, 0.25 \mathrm{~m}, 0.5 \mathrm{~m}$, and $1 \mathrm{~m}$ are carried out. The cavities have a constant temperature back wall boundary condition. The cavities are fully open (opening ratio of 1 ) and are inclined at different inclinations (downward facing). Rayleigh numbers in the range of $4.5 \times 10^{5}-1.5 \times 10^{9}$ are studied. Nusselt number correlations that involve Rayleigh numbers and the inclination effects are proposed. These correlations can be used for engineering applications such as electronic cooling, low- and medium-temperature solar thermal systems, passive architecture, and also refrigeration systems.

\section{Problem Description}

Open cubical cavities of sides $0.1 \mathrm{~m}, 0.2 \mathrm{~m}, 0.25 \mathrm{~m}, 0.5 \mathrm{~m}$, and $1 \mathrm{~m}$ are used for the study. The numerical analysis is performed with a constant temperature back wall boundary

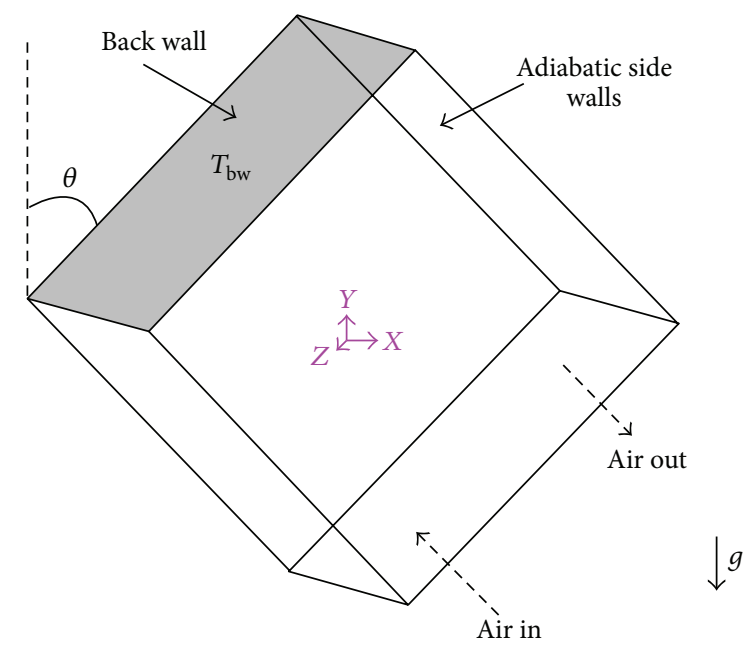

FIGURE 1: Schematic of the open cubical cavity inclined downwards at an angle $\theta$.

condition. The convective loss from each open cubical cavity is analysed for different back wall temperatures between $35^{\circ} \mathrm{C}$ and $100^{\circ} \mathrm{C}$. The inclination effect on the convective loss for each back wall temperature case is studied for five different cavity inclinations: $0^{\circ}$ (sideways facing cavity), $30^{\circ}, 45^{\circ}, 60^{\circ}$, and $90^{\circ}$ (vertically downward facing cavity). The ambient temperature is kept constant at $30^{\circ} \mathrm{C}$. The Rayleigh number range is between $4.5 \times 10^{5}$ and $1.5 \times 10^{9}$. The aperture height of each cavity is equal to the cavity side, thus making them fully open cavities $(a / H=1)$. Figure 1 shows the schematic of the open cubical cavity with back wall temperature $T_{\mathrm{bw}}$ and inclined downwards at an angle $\theta$.

It is seen from the literature that the numerical analyses of natural convection losses in solar cavity receiver [26, 27, 31] have been performed using the Fluent CFD [36] software. The appropriateness of using Fluent CFD software for the present numerical study, therefore, needs to be checked. In order to check this, a study from the literature (Hinojosa et al. [5]) is used. The work of Hinojosa et al. [5] refers to the threedimensional (3D) numerical study of open cubical cavities with constant temperature back wall boundary condition. The analysis by Hinojosa et al. [5] was performed for Rayleigh numbers between $10^{4}$ and $10^{7}$ and for cavity inclinations between $-90^{\circ}$ (vertically upward facing cavity) and $90^{\circ}$ (vertically downward facing cavity). Hinojosa et al. [5] performed numerical analysis using the finite-volume method, the SIMPLEC algorithm, the SMART scheme, and the central differencing scheme.

A cubical open cavity is modelled using the Gambit tool of the Fluent CFD software [36]. The model is analysed using the Fluent CFD software for Rayleigh numbers equal to $10^{5}$ and three inclination angles (0, 45, and 90 degrees). The temperature profiles obtained from the Fluent CFD model are compared with those reported by Hinojosa et al. [5] at $\mathrm{Ra}=$ $10^{5}$ and cavity inclinations of 0,45 , and 90 degrees. Figure 2 shows the temperature profiles obtained from Hinojosa et al. [5] and the Fluent CFD model for the cubical cavity (cavity 


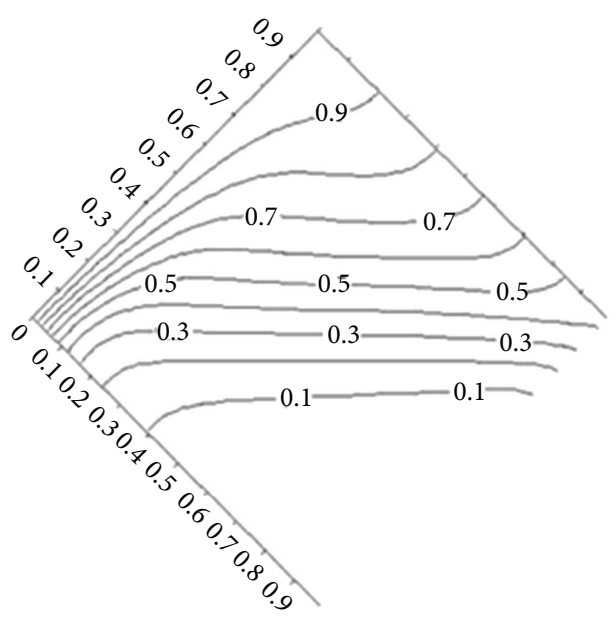

Hinojosa et al. [5]

(a)

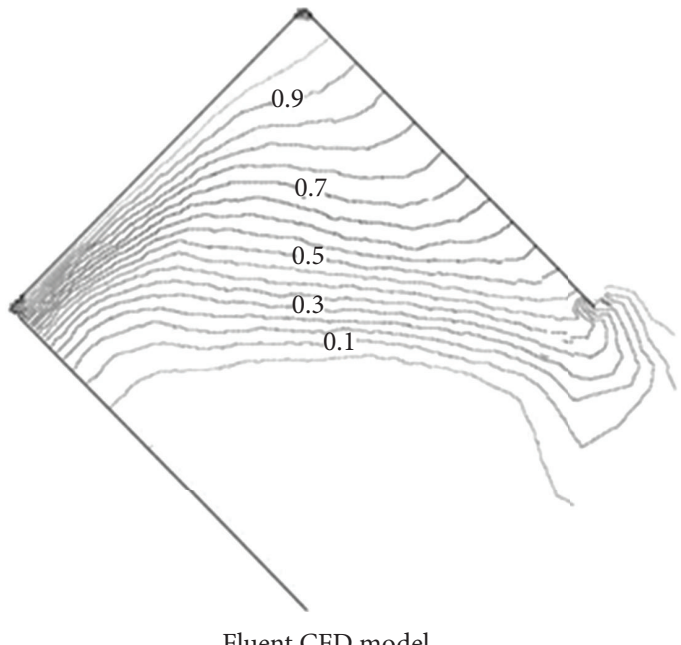

(b)

FIgURE 2: Comparison of temperature profiles at the midplane of the cavities at $45^{\circ}$ inclination and Rayleigh number of $10^{5}$.

midplane) inclined at $45^{\circ}$. A good agreement is observed. The maximum variation between the Nusselt numbers obtained from the Fluent CFD model and Hinojosa et al. [5] is about $7 \%$. It can, therefore, be concluded from this preliminary study that the Fluent CFD software can be used to analyse natural convection heat transfer in cubical open cavities with constant temperature back wall boundary condition and different cavity inclinations.

\section{Numerical Scheme}

3D numerical models of the open cubical cavities of sides $0.1 \mathrm{~m}, 0.2 \mathrm{~m}, 0.25 \mathrm{~m}, 0.5 \mathrm{~m}$, and $1 \mathrm{~m}$ are created using the Gambit tool [36]. The initial boundary condition at the aperture is unknown; hence, an enclosure, cubical in shape, representing the ambient is also modelled for each cavity in Gambit. An initial study is performed to determine the optimal dimensions of the enclosure. It is observed that an enclosure dimension ten times the cavity side affects the convection occurring within the cavity while this is not observed for enclosures having dimensions equal to and above 15 times the cavity side. Hence, an enclosure with sides having dimensions equal to fifteen times the cavity side dimension is chosen for the analysis. The mesh chosen for the analysis is nonuniform with the areas close to the cavity having a smooth mesh (mesh interval size of about 10) while the mesh is coarse at the enclosure walls (mesh interval size of about 300). These mesh sizes are chosen from a grid independence study performed on a $0.25 \mathrm{~m}$ cubic cavity with $\mathrm{Ra}$ of $2.4 \times 10^{7}$. The number of cells used for the simulations is of the order of $2 \times 10^{5}$. Figure 3 shows a sample of the internal and external mesh used for the numerical analysis. It can be seen from the figure that the mesh is made to progressively coarsen from the cavity to the enclosure walls.

The transition from laminar to turbulent flow in natural convection heat transfer from heated plates is reported in the literature and is dependent on the orientation of the plate (vertical, upward and downward facing horizontal, and inclined). In an open cavity, the heated wall is surrounded by other walls and the heated wall position changes with the cavity inclination (at $0^{\circ}$ cavity inclination, the heated wall is vertical while it is horizontal at $90^{\circ}$ inclination). It is, therefore, observed that the Rayleigh number at which flow transition occurs from laminar flow to turbulent flow in open cavities is not well defined. Therefore in this paper, a laminar model is assumed for Rayleigh numbers below $1 \times 10^{9}$ and the $k-\varepsilon$ turbulence model for higher Rayleigh numbers.

The cavity wall material is chosen as copper while air $(\mathrm{Pr}=0.7)$ is the fluid within the cavity and the enclosure. Kothandaraman and Subramanyan [37] have been referred for the material properties used in this study. The Boussinesq approximation for air properties is used. The gravity vector is adjusted so as to perform the analysis at different inclinations.

The general equations describing the conservation of mass, momentum, and energy are given as (Kakac et al. [38])

$$
\begin{gathered}
\nabla \cdot V=0, \\
V \cdot \nabla V=f-\frac{\nabla P}{\rho}+v \nabla^{2} V, \\
\nabla \cdot(k \nabla T)=0 .
\end{gathered}
$$

The numerical simulations are based on the simultaneous solutions of the above-mentioned equation (1).

The boundary conditions used for the numerical analysis are as follows:

(1) cavity back wall temperature is specified,

(2) other four cavity walls are adiabatic,

(3) the cavity walls are insulated from the outside, and

(4) enclosure walls are maintained at ambient temperature $\left(T_{a}=30^{\circ} \mathrm{C}\right)$. 


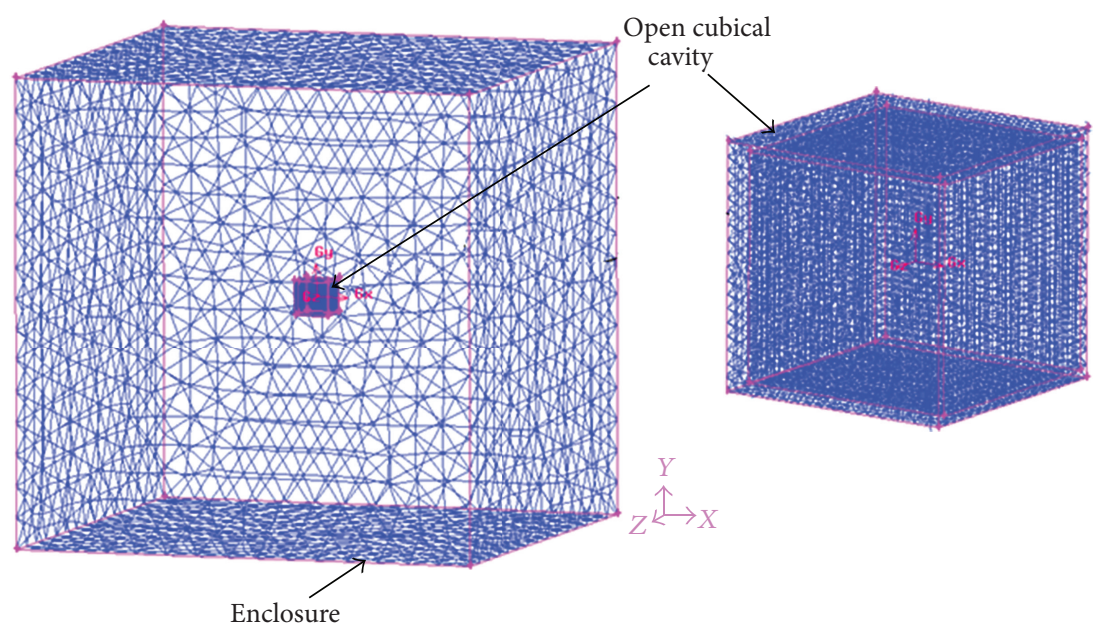

FIgURE 3: The mesh used for the open cubical cavity at $0^{\circ}$ inclination along with the enclosure.

The Semi-Implicit Pressure-Linked Equation (SIMPLE) scheme of Fluent software is used for the numerical analysis. The SIMPLE scheme is found to be more suited for complicated problems involving laminar, transitional, and turbulent flow. The scheme involves a pressure-velocity coupling and is stable than other pressure-velocity coupling schemes. It is used along with a segregated solver for steady-state problems. First-order upwind momentum and energy solution controls are used in order to reduce the convergence time. The convergence criterion set for the residuals is of the order of $10^{-3}$ for the continuity and the velocity equations while for the energy equation it is $10^{-6}$. The simulations are complete once the convergence criteria are satisfied. The convective loss values are then obtained from the simulations.

In the present study, the numerical analysis is performed on 3D cubical cavity models with constant temperature back wall boundary condition. The back wall temperatures range between $35^{\circ} \mathrm{C}$ and $100^{\circ} \mathrm{C}$ and the ambient temperature is $30^{\circ} \mathrm{C}$. For each constant temperature back wall case, the cavity is inclined at five angles $\left(0,30,45,60\right.$, and $\left.90^{\circ}\right)$. The steadystate convective losses are then obtained from the numerical simulations.

\section{Results and Discussion}

The convective loss due to buoyancy from open cubical cavities of side $0.1 \mathrm{~m}$ is shown in Figure 4. It is observed that the convective losses increases with an increase in $\Delta T(\Delta T=$ $T_{\mathrm{bw}}-T_{a}$ ) value. This is valid for all cavity sizes. It is also seen that the convective losses decrease with an increase in cavity inclination; the highest loss at $0^{\circ}$ and the least at $90^{\circ}$. The relation between the convective loss and inclination is nonlinear. This is similar to the findings by Hinojosa et al. [5]. Figure 5 shows the convective loss trends for the cavity with side $0.5 \mathrm{~m}$ and $\Delta T$ of $20^{\circ} \mathrm{C}$ and $70^{\circ} \mathrm{C}$. Similar trends are observed for all cubical cavities analysed here.

The decrease in convective loss with an increase in cavity inclination is due to the presence of stagnation and convective zones within the cavity. The convective losses occur from the

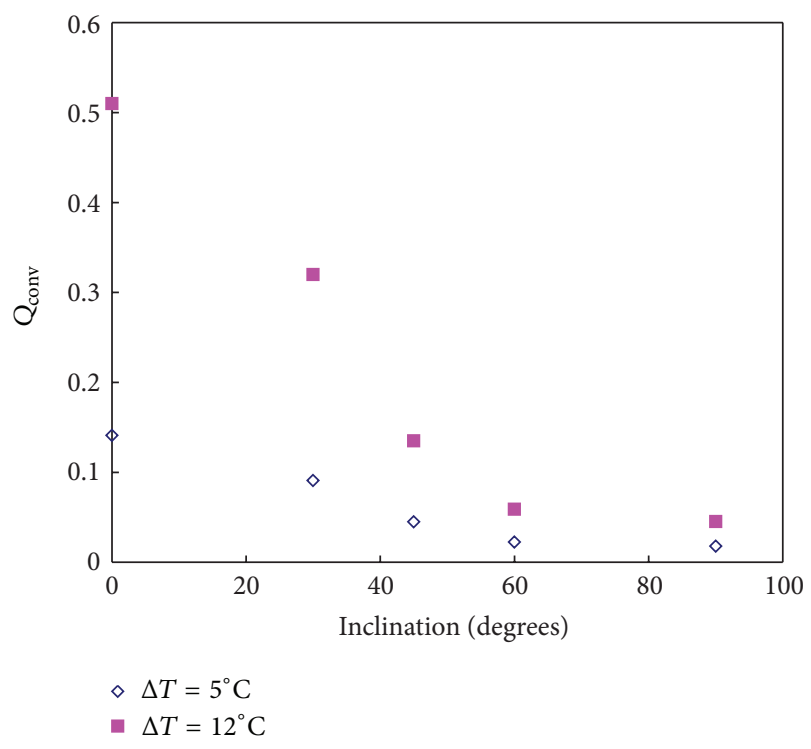

FIgURE 4: Variation of the convective loss (in Watts) with $\Delta T$ and inclination for open cubical cavity of side $0.1 \mathrm{~m}$.

convective zone. It is observed from the temperature profiles that there is a stagnation zone at the topmost part of the cavity and this zone area increases with cavity inclination. The convective zone area on the other hand decreases with cavity inclination leading to a decrease in convective loss. This can be observed from Figure 6 where the temperature profiles along with the nondimensional air temperature values $\left(\left(T_{\mathrm{air}, i}-T_{a}\right) /\left(T_{\mathrm{bw}}-T_{a}\right)\right)$ are shown for a cubical cavity of $0.5 \mathrm{~m}$ side, $T_{\mathrm{bw}}=100^{\circ} \mathrm{C}$ and inclined at different angles. The temperature profiles obtained from other cubical cavities analysed here also show similar trends.

The average heat transfer coefficient $(h)$ is calculated for each case:

$$
h=\frac{Q_{\mathrm{conv}}}{A_{\mathrm{bw}}\left(T_{\mathrm{bw}}-T_{a}\right)}
$$




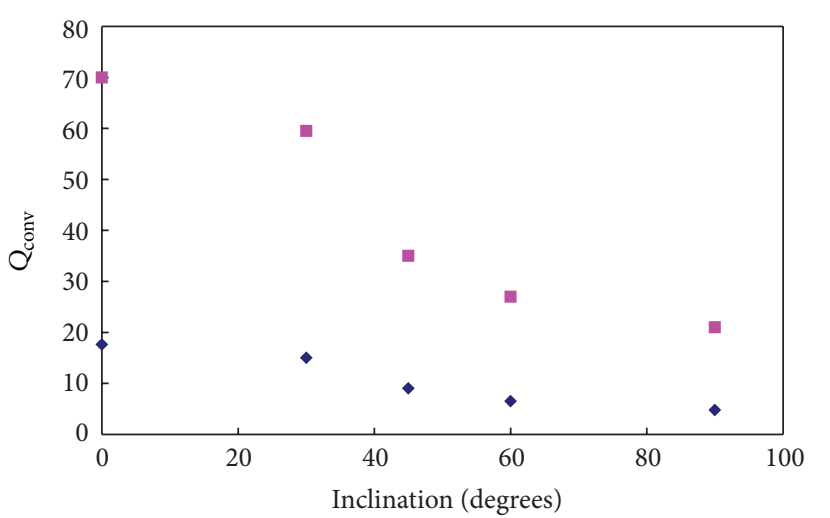

- $\Delta T=20^{\circ} \mathrm{C}$

- $\Delta T=70^{\circ} \mathrm{C}$

Figure 5: Variation of the convective loss (in Watts) with $\Delta T$ and inclination for open cubical cavity of side $0.5 \mathrm{~m}$.

where $Q_{\text {conv }}$ is the natural convection loss, $A_{\mathrm{bw}}$ is the area of the cavity back wall, $T_{\mathrm{bw}}$ is the back wall temperature, and $T_{a}$ is the ambient temperature.

The average Nusselt number based on the cavity height $\left(\mathrm{Nu}_{H}\right)$ is then calculated:

$$
\mathrm{Nu}_{H}=\frac{h H}{k}
$$

where $H$ is the height (side) of the cubical cavity and $k$ is the thermal conductivity of air. All air properties are obtained at the film temperature $T_{f}$ (Clausing et al. [4]), where $T_{f}=$ $0.5\left(T_{\mathrm{bw}}+T_{a}\right)$.

The Rayleigh number is calculated based on the cavity height $(H)$ :

$$
\mathrm{Ra}_{H}=\frac{g \beta \Delta T H^{3}}{v^{2}} \operatorname{Pr},
$$

where $g$ is the gravitation acceleration, $\beta$ is the volume coefficient of expansion, $v$ is the kinematic viscosity, and $\operatorname{Pr}$ is the Prandtl number ( 0.7 for air). The range of Rayleigh number is between $4.5 \times 10^{5}$ and $1.5 \times 10^{9}$.

A comparison of the Nusselt number values obtained from the present simulation and those reported by Hinojosa et al. [5] for $\mathrm{Ra}_{H}=1 \times 10^{6}$ is shown in Table 1 . The maximum variation is about $10 \%$. It is also observed that there are convective currents at the cavity aperture at $90^{\circ}$ inclination, and hence the cavity is not fully in the stagnation zone. This leads to very low convective loss values and hence the lowest average Nusselt numbers when compared to other inclinations.

It is realized that correlations between the calculated Nusselt number and the Rayleigh number are important for determining or predicting the convective loss from open cubical cavities with constant temperature back wall conditions. The inclination effect on the convective loss also needs to be incorporated in the correlations so that the convective losses at different inclinations (for downward facing cavities)
TABLE 1: Comparison of the Nusselt number values obtained from the present simulation and those reported by Hinojosa et al. [5] for $\mathrm{Ra}_{H}=1 \times 10^{6}$ at different inclinations.

\begin{tabular}{lccc}
\hline Inclination & $\begin{array}{c}\text { Nusselt number } \\
\text { from present } \\
\text { simulation }\end{array}$ & $\begin{array}{c}\text { Nusselt number } \\
\text { from Hinojosa et al. } \\
{[5]}\end{array}$ & $\begin{array}{c}\text { Variation } \\
(\%)\end{array}$ \\
\hline $0^{\circ}$ & 15.74 & 14.33 & 9.83 \\
$30^{\circ}$ & 9.88 & 9.55 & 3.45 \\
$45^{\circ}$ & 4.17 & 4.32 & 3.47 \\
$60^{\circ}$ & 1.82 & 1.86 & 2.15 \\
$90^{\circ}$ & 1.39 & 1.45 & 4.13 \\
\hline
\end{tabular}

can be determined accurately. In this study, Nusselt number correlations are developed by regression analysis. The correlations take into account the Rayleigh numbers and the inclination effect. The correlations will be relevant for open cubical cavities used in solar thermal conversion systems, passive architecture and electronic cooling applications.

The Rayleigh numbers involved in these studies range between $4.5 \times 10^{5}$ and $1.5 \times 10^{9}$, and a single correlation between the Nusselt number, the Rayleigh number, and all the inclination angles for this entire range is not possible. Therefore, two correlations involving the Nusselt number, the Rayleigh number, and the inclination angles are proposed for two ranges of Rayleigh numbers: (i) $4.5 \times 10^{5} \leq \mathrm{Ra}_{H} \leq 1 \times$ $10^{7}$ and (ii) $2.5 \times 10^{7} \leq \mathrm{Ra}_{H} \leq 1.5 \times 10^{9}$. A correlation for the entire range of Rayleigh numbers $\left(4.5 \times 10^{5}-1.5 \times 10^{9}\right)$ is only possible for the $0^{\circ}$ inclination case.

The variation of Nusselt numbers with Rayleigh numbers for different inclination values can be seen from Figure 7. It is observed that the Nusselt numbers in the lower Rayleigh number range $\left(4.5 \times 10^{5} \leq \mathrm{Ra}_{H} \leq 1 \times 10^{7}\right)$ for the $90^{\circ}$ inclination cases are negligible when compared to the Nusselt numbers for other inclination angles. This could be due the fact that at these Rayleigh numbers, the heat transfer at $90^{\circ}$ inclination is predominantly conducted based on minimal convective currents at the cavity aperture and is the least when compared to the other inclinations, where heat transfer is due to convective currents within the cavity. The coefficient of determination is very low (about 0.8 ) when a Nusselt number correlation is developed for all the inclination angles. Therefore, the Nusselt number correlation for this range of Rayleigh number $\left(4.5 \times 10^{5}-1 \times 10^{7}\right)$ is limited to inclination angles $(\theta)$ between $0^{\circ}$ and $60^{\circ}$ and is given by

$$
\mathrm{Nu}_{H}=0.143 \mathrm{Ra}_{H}^{(1 / 3)}(\cos \theta)^{3.0} .
$$

The Nusselt numbers at $90^{\circ}$ inclination in the higher Rayleigh number range $\left(2.5 \times 10^{7}-1.5 \times 10^{9}\right)$ are the least when compared to other inclination angles. The values though low are significant as there are convective currents near the cavity aperture leading to heat transfer by convection. The Nusselt number correlation in this Rayleigh number range is proposed for all inclinations between $0^{\circ}$ and $90^{\circ}$ and is given by

$$
\mathrm{Nu}_{H}=0.024 \mathrm{Ra}_{H}^{(1 / 3)}(1+\cos \theta)^{1.96}
$$




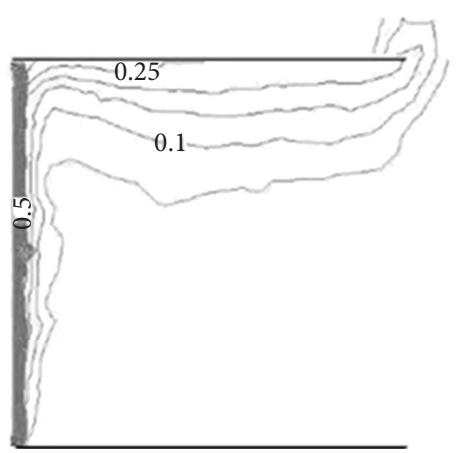

$0^{\circ}$

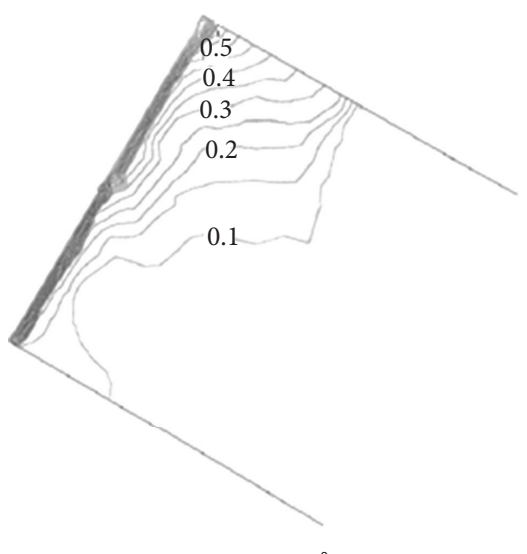

$30^{\circ}$

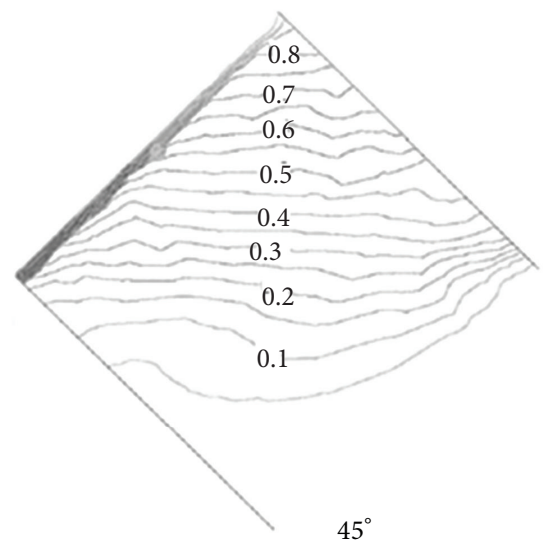

$45^{\circ}$

(a)

(b)

(c)

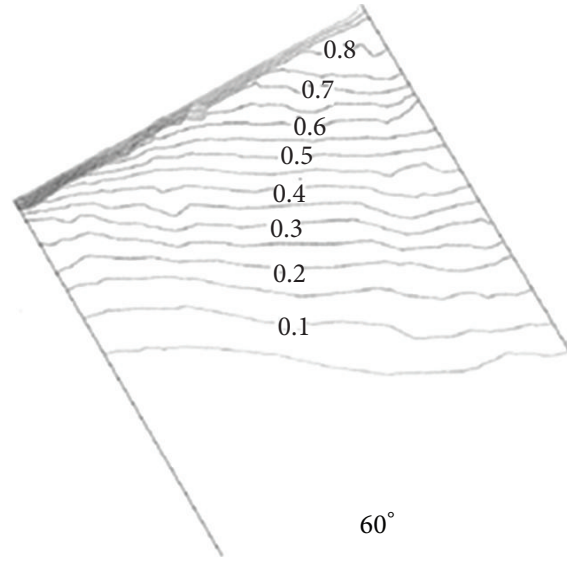

(d)

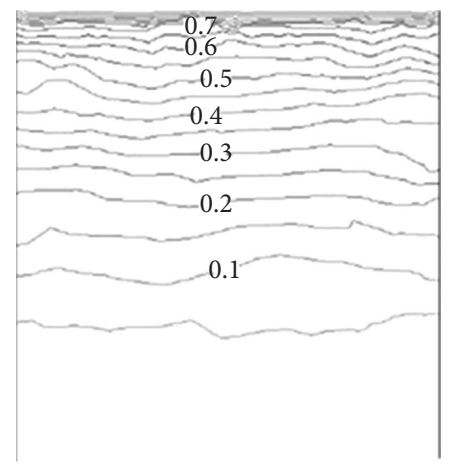

$90^{\circ}$

(e)

FIgURE 6: Temperature profiles at different inclinations for open cubical cavity of side $0.5 \mathrm{~m}$ and $T_{\mathrm{bw}}=100^{\circ} \mathrm{C}$.

The parity plots for both the correlations are shown in Figure 8 . The coefficient of determination is about 0.93 . It is noticed that a Nusselt number correlation is possible for the entire range of Rayleigh numbers $\left(4.5 \times 10^{5}-1.5 \times 10^{9}\right)$ for the $0^{\circ}$ inclination cases. This correlation is only suitable to predict the convective losses from the sideways facing open cubical cavity with constant temperature back wall boundary condition. The correlation proposed is

$$
\mathrm{Nu}_{H}=0.513 \mathrm{Ra}_{H}^{0.252} .
$$

All the correlations are developed for $\left(T_{\mathrm{bw}} / T_{a}\right)$ range between 1.03 and 1.23, where the temperature values are in Kelvin.

The applicability of the correlations proposed in this study is checked by comparing the Nusselt number from the correlations with the results already available in the literature. The Nusselt numbers predicted by (5) for Rayleigh numbers of $10^{6}$ and $10^{7}$ and inclinations between $0^{\circ}$ and $60^{\circ}$ are compared with those reported by Hinojosa et al. [5]. It is observed that the maximum variation between the predicted Nusselt numbers and those obtained numerically by Hinojosa et al. [5] for Rayleigh number of $10^{6}$ is about $15 \%$. At Rayleigh number $10^{7}$, the agreement is good for lower inclination values but the variation is high for angles of $45^{\circ}$ and $60^{\circ}$. A better agreement is observed when the predicted Nusselt number values for $45^{\circ}$ and $60^{\circ}$ inclinations are compared with those obtained from the correlation suggested by Hinojosa et al. [5] .

The predicted Nusselt number values obtained from (5) for Rayleigh number of $10^{6}$ at $0^{\circ}$ inclination is compared with those reported in the literature $[13,20]$. The studies by Comini et al. [13] and Chan and Tien [20] are for open rectangular and square cavities with constant temperature back wall boundary condition. A Nusselt number value of 14.3 is obtained from (5), while the values from Comini et al. [13] and Chan and Tien [20] are 14.7 and 15, respectively. The Nusselt number value calculated using (5) for Rayleigh number of $10^{7}$ and inclination of $0^{\circ}$ is 30.8 while the values reported by Chan and Tien [20] are 28.6 and 30.7 by Polat and Bilgen [35]. The Nusselt number value reported by Chakroun et al. [14] for a sideway facing rectangular open cavity at 


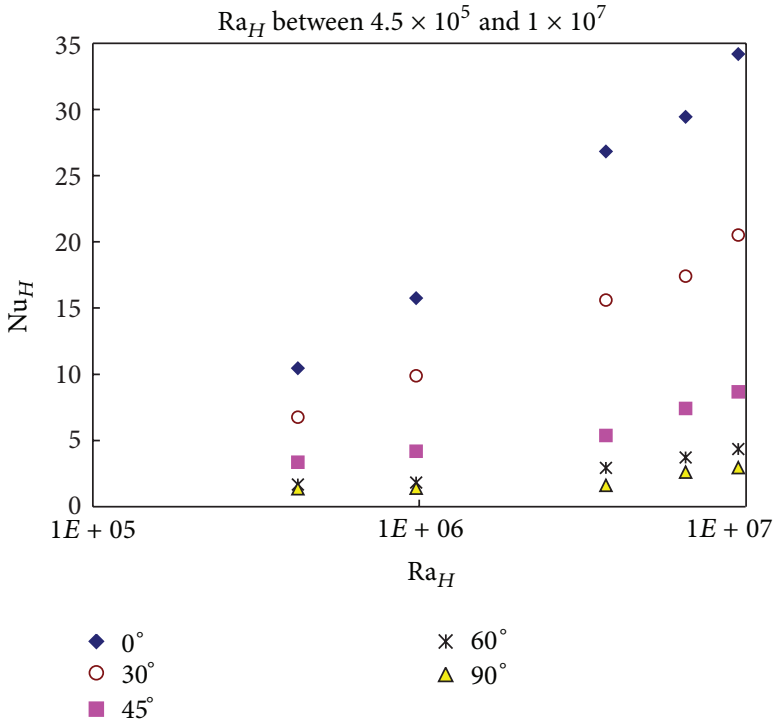

(a)

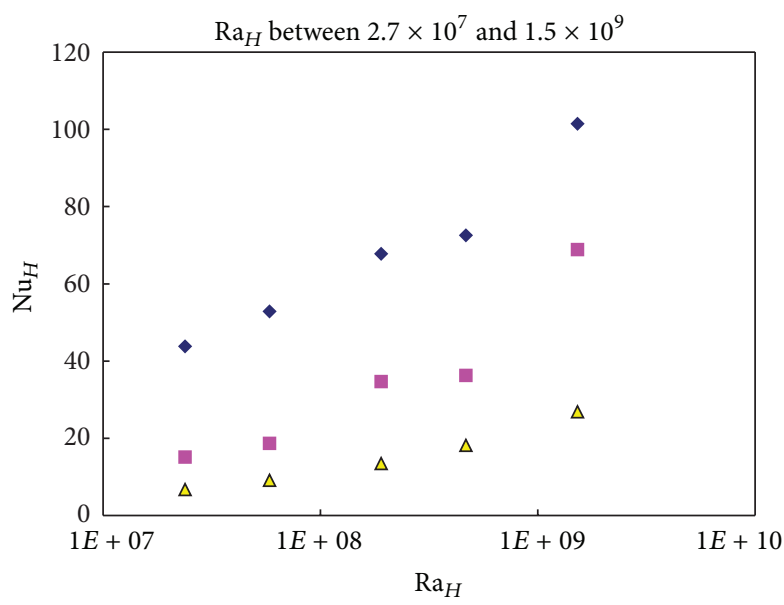

- $0^{\circ}$

- $45^{\circ}$

$\triangle 90^{\circ}$

FIgURE 7: Variation of the $\mathrm{Nu}_{H}$ with $\mathrm{Ra}_{H}$ for different inclinations.

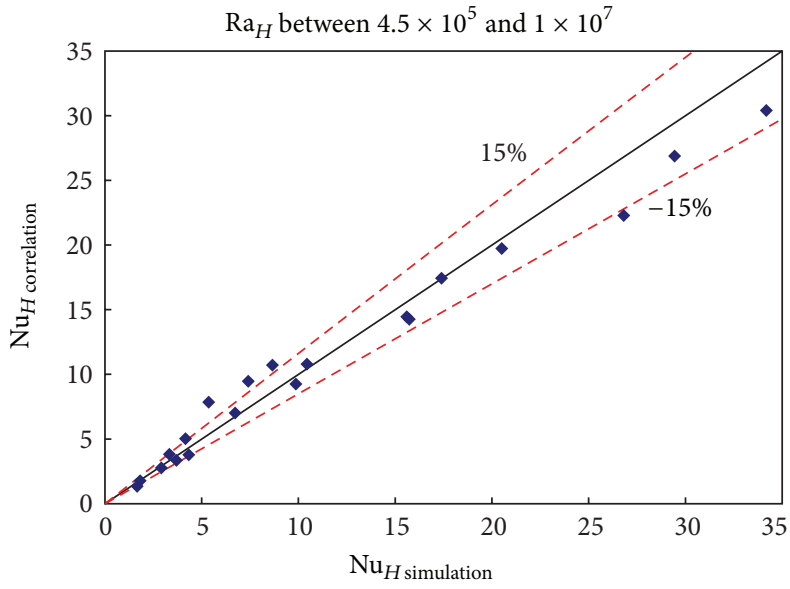

(a)

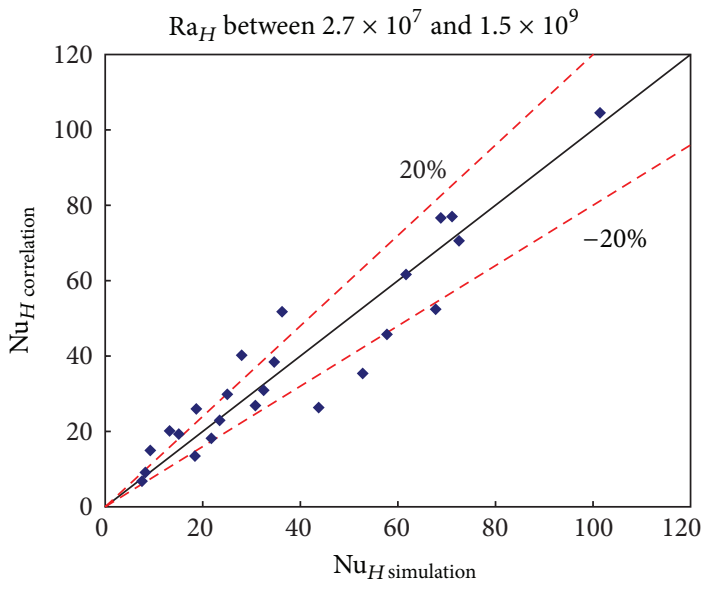

(b)

FIgURE 8: Parity plots of $\mathrm{Nu}_{H \text { simulation }}$ and $\mathrm{Nu}_{H \text { correlation }}$.

Rayleigh number of $0.63 \times 10^{7}$ is 24 while from (5), the value obtained is 26.4 .

It was reported earlier in this paper that studies involving the inclination effect on convective losses from downward facing open cavities with constant temperature back wall boundary condition are limited to Rayleigh numbers of $1 \times$ $10^{7}$. Therefore, the Nusselt number values obtained from the correlation developed for the higher Rayleigh number ranges (6) are compared with those reported in the literature only for $0^{\circ}$ inclination. At Rayleigh number of $10^{8}$, the Nusselt number value from (6) is 43.4 while the values from literature are 56.8 [20] and about 40 [23]. The Nusselt number value from (6) at Rayleigh number of $10^{9}$ is 93.3 while from the literature the value is 105 [20]. The comparison between the
Nusselt numbers obtained from (7) and Chan and Tien [20] for open cavities at $0^{\circ}$ inclination, constant temperature back wall boundary condition, and Rayleigh numbers between $1 \times$ $10^{6}$ and $1 \times 10^{9}$ is shown in Table 2 .

It is, therefore, observed that the Nusselt numbers predicted by the correlations proposed in this paper have a fairly good agreement to those reported in the literature. The variations between the Nusselt numbers obtained from the correlations proposed in this study and the literature may be due to the difference in the numerical schemes used for the analysis and also due to the difference in the modelling itself (present study is 3D while Chan and Tien [20] analyses a $2 \mathrm{D}$ model). It is also seen that the correlations can be used for other shapes like square and rectangular cavities inclined 
TABle 2: Comparison of predicted Nusselt numbers with those reported by Chan and Tien [20].

\begin{tabular}{lcc}
\hline Rayleigh number & Nusselt number (7) & Nusselt number [20] \\
\hline $1 \times 10^{6}$ & 16.6 & 15.0 \\
$1 \times 10^{7}$ & 29.8 & 28.6 \\
$1 \times 10^{8}$ & 53.2 & 56.8 \\
$1 \times 10^{9}$ & 95 & 105 \\
\hline
\end{tabular}

at $0^{\circ}$ for Rayleigh numbers between $1 \times 10^{6}$ and $1 \times 10^{9}$ with fairly good accuracy.

\section{Conclusions}

In this paper, numerical studies on the natural convection loss from open cubical cavities having constant temperature back wall boundary condition are carried out. The effect of the different back wall temperatures and cavity inclinations (between $0^{\circ}$ and $90^{\circ}$ ) on the convection loss is studied. The following conclusions can be drawn from this study.

(i) It is observed that the convective loss increases with an increase in $\Delta T$ value. This is observed for all cavity sizes and inclination angles. The convective loss values for all inclinations can increase by a factor between 5 and 8 (based on the cavity size) when $\Delta T$ increases by about $50^{\circ} \mathrm{C}$.

(ii) It is also seen that the convective losses decrease with an increase in cavity inclination; the highest loss at $0^{\circ}$ and the least at $90^{\circ}$. This is due to the increase in stagnation zone area and decrease in convective zone area with an increase in cavity inclination. It is observed that the convective loss values at $90^{\circ}$ inclination for different cavity sizes and temperature values can vary between 8 and $30 \%$ of the convective loss at $0^{\circ}$ inclination.

(iii) Nusselt number correlations involving Rayleigh numbers and cavity inclinations are developed. Correlations are proposed for a low Rayleigh number range $\left(4.5 \times 10^{5}-1 \times 10^{7}\right)$ and higher range of Rayleigh number $\left(2.5 \times 10^{7}-1.5 \times 10^{9}\right)$. A correlation for the $0^{\circ}$ inclination angle (sideways facing cavity) is also proposed for the entire range of Rayleigh numbers analysed here $\left(4.5 \times 10^{5}-1.5 \times 10^{9}\right)$.

(iv) The Nusselt numbers predicted by the correlations are compared with the limited data available in the literature. A good agreement is observed with maximum variation of about $20 \%$.

\section{Nomenclature}

$A_{\mathrm{bw}}:$ Area of the back wall $\left(\mathrm{m}^{2}\right)$

$a$ : Height of cavity aperture opening (cubical, rectangular, and square cavities) (m)
D: $\quad$ Diameter of open cavity (cylindrical, spherical, and hemispherical cavities) (m)

$d$ : $\quad$ Diameter of the cavity aperture opening (cylindrical, spherical, and hemispherical cavities) $(\mathrm{m})$

$a / H, d / D$ : Opening ratio

$f: \quad$ Body force per unit mass

$g: \quad$ Gravitational acceleration $\left(\mathrm{m} / \mathrm{s}^{2}\right)$

$H$ : $\quad$ Height of cavity (cubical, rectangular, and square cavities) (m)

$h$ : Convective heat transfer coefficient

$\left(\mathrm{W} / \mathrm{m}^{2}-\mathrm{K}\right)$

$k: \quad$ Thermal conductivity $(\mathrm{W} / \mathrm{m}-\mathrm{K})$

$\mathrm{Nu}_{H}$ : Nusselt number based on cavity height

P: $\quad$ Pressure $\left(\mathrm{N} / \mathrm{m}^{2}\right)$

Pr: $\quad$ Prandtl number

$Q_{\text {conv }}$ : Convective loss (W)

$\mathrm{Ra}_{H}$ : Rayleigh number based on cavity height

$T_{a}: \quad$ Ambient temperature $\left({ }^{\circ} \mathrm{C}\right)$

$T_{\text {air }, i}$ : Air temperature at a point " $i$ " within the

$\begin{array}{ll}T_{f}: & \text { cavity }\left({ }^{\circ} \mathrm{C}\right) \\ & \text { Film temperature }\left({ }^{\circ} \mathrm{C}\right)\end{array}$

$T_{\text {bw }}$ : $\quad$ Cavity back wall temperature $\left({ }^{\circ} \mathrm{C}\right)$

$V: \quad$ Velocity vector.

Greek Symbols

$\beta$ : $\quad$ Volume coefficient of expansion $(1 / \mathrm{K})$

$\Delta T$ : Temperature difference $\left(T_{\mathrm{bw}}-T_{a}\right)$

$v$ : Kinematic viscosity $\left(\mathrm{m}^{2} / \mathrm{s}\right)$

$\theta: \quad$ Cavity inclination (degrees).

\section{Acknowledgment}

The author wishes to thank Professor J. K. Nayak and Professor S. B. Kedare of Department of Energy Science and Engineering, Indian Institute of Technology Bombay, India, for their immense help and support.

\section{References}

[1] P. Le Quere, F. Penot, and M. Mirenayat, "Experimental study of heat loss through natural convection from an isothermal cubic open cavity," Proceedings DOE/SERI/SNLL Workshop on Convective Losses from Solar Receivers, Sandia Laboratory Report SAND81-8014, Livermore, California, Calif, USA, 1981.

[2] M. Abrams and R. Greif, "A simple theory for predicting the natural convective energy loss from side-facing cavity receivers," Proceedings DOE/SERI/SNLL Workshop on Convective Losses from Solar Receivers, Sandia Laboratory Report SAND81-8014, Livermore, California, Calif, USA, 1981.

[3] C. F. Hess and R. H. Henze, "Experimental investigations of natural convection losses from open cavities," Journal of Heat Transfer, vol. 106, no. 2, pp. 333-338, 1984.

[4] A. M. Clausing, J. M. Waldvogel, and L. D. Lister, "Natural convection from isothermal cubical cavities with a variety of sidefacing apertures," Journal of Heat Transfer, vol. 109, no. 2, pp. 407-412, 1987. 
[5] J. F. Hinojosa, G. Alvarez, and C. A. Estrada, "Three-dimensional numerical simulation of the natural convection in an open tilted cubic cavity," Revista Mexicana de Fisica, vol. 52, no. 2, pp. 111-119, 2006.

[6] W. Terrell Jr. and T. A. Newell, "Localized heat transfer in buoyancy driven convection in open cavities," Journal of Heat Transfer, vol. 129, no. 2, pp. 167-178, 2007.

[7] L. L. Eyler, "Predictions of convective losses from a solar cavity receiver," Proceedings DOE/SERI/SNLL Workshop on Convective Losses from Solar Receivers, Sandia Laboratory Report SAND81-8014, Livermore, California, Calif, USA, 1981.

[8] A. M. Clausing, "Convective losses from cavity solar receiverscomparisons between analytical predictions and experimental results," Journal of Solar Energy Engineering, vol. 105, no. 1, pp. 29-33, 1983.

[9] K. S. Chen, J. A. C. Humphrey, and F. S. Sherman, "Free and mixed convective flow or air in a heated cavity of variable rectangular cross section and orientation," Philosophical Transactions of the Royal Society of London A, vol. 316, pp. 57-84, 1985.

[10] Y. L. Chan and C. L. Tien, "A numerical study of two-dimensional laminar natural convection in shallow open cavities," International Journal of Heat and Mass Transfer, vol. 28, no. 3, pp. 603-612, 1985.

[11] Y. L. Chan and C. L. Tien, "Laminar natural convection in shallow open cavities," Journal of Heat Transfer, vol. 108, no. 2, pp. 305-309, 1986.

[12] H. Skok, S. Ramadhyani, and R. J. Schoenhals, "Natural convection in a side-facing open cavity," International Journal of Heat and Fluid Flow, vol. 12, no. 1, pp. 36-45, 1991.

[13] G. Comini, G. Cortella, and M. Manzan, "Natural convection in rectangular open cavities," Transactions on Engineering Sciences, vol. 12, pp. 13-22, 1996.

[14] W. Chakroun, M. M. Elsayed, and S. F. Al-Fahed, "Experimental measurements of heat transfer coefficient in a partially/fully opened tilted cavity," Journal of Solar Energy Engineering, vol. 119, no. 4, pp. 298-303, 1997.

[15] M. M. Elsayed and W. Chakroun, "Effect of aperture geometry on heat transfer in tilted partially open cavities," Journal of Heat Transfer, vol. 121, no. 4, pp. 819-827, 1999.

[16] O. Polat and E. Bilgen, "Conjugate heat transfer in inclined open shallow cavities," International Journal of Heat and Mass Transfer, vol. 46, no. 9, pp. 1563-1573, 2003.

[17] W. Chakroun, "Effect of boundary wall conditions on heat transfer for fully opened tilted cavity," Journal of Heat Transfer, vol. 126, no. 6, pp. 915-923, 2004.

[18] P. Le Quere, J. A. C. Humphrey, and F. S. Sherman, "Numerical calculation of thermally driven two-dimensional unsteady laminar flow in cavities of rectangular cross section," Numerical Heat Transfer, vol. 4, no. 3, pp. 249-283, 1981.

[19] F. Penot, "Numerical calculation of two-dimensional natural convection in isothermal open cavities," Numerical Heat Transfer, vol. 5, no. 4, pp. 421-437, 1982.

[20] Y. L. Chan and C. L. Tien, "A numerical study of two-dimensional natural convection in square open cavities," Numerical Heat Transfer, vol. 8, no. 1, pp. 65-80, 1985.

[21] J. A. C. Humphrey and W. M. To, "Numerical simulation of buoyant, turbulent flow-II. Free and mixed convection in a heated cavity," International Journal of Heat and Mass Transfer, vol. 29, no. 4, pp. 593-610, 1986.

[22] M. Miyamoto, T. H. Kuehn, R. J. Goldstein, and Y. Katoh, “Twodimensional laminar natural convection heat transfer from a fully or partially open square cavity," Numerical Heat Transfer A, vol. 15, no. 4, pp. 411-430, 1989.

[23] D. Angirasa, M. J. B. M. Pourquie, and F. T. M. Nieuwstadt, "Numerical study of transient and steady laminar buoyancydriven flows and heat transfer in a square open cavity," Numerical Heat Transfer A, vol. 22, no. 2, pp. 223-239, 1992.

[24] E. Bilgen and H. Oztop, "Natural convection heat transfer in partially open inclined square cavities," International Journal of Heat and Mass Transfer, vol. 48, no. 8, pp. 1470-1479, 2005.

[25] T. Taumoefolau and K. Lovegrove, "An experimental study of natural convection heat loss from a solar concentrator cavity receiver at varying orientation," in Proceedings of the Annual Conference of the Australian and New Zealand Solar Energy Society (ANZSES' 02), Newcastle, Australia, 2002.

[26] S. Paitoonsurikarn and K. Lovegrove, "Numerical investigation of natural convection loss in cavity-type solar receivers," in Proceedings of the Annual Conference of the Australian and New Zealand Solar Energy Society (ANZSES’ 02), Newcastle, Australia, 2002.

[27] M. Prakash, S. B. Kedare, and J. K. Nayak, "Investigations on heat losses from a solar cavity receiver," Solar Energy, vol. 83, no. 2, pp. 157-170, 2009.

[28] W. B. Stine and C. G. McDonald, "Cavity receiver convective heat loss," Proceedings of International Solar Energy Society Solar World Congress, vol. 2, pp. 1318-1322, 1989.

[29] C. G. McDonald, "Heat loss from an open cavity," Sandia National Laboratories Report SAND95-2939, 1995.

[30] U. Leibfried and J. Ortjohann, "Convective heat loss from upward and downward-facing cavity solar receivers: measurements and calculations," Journal of Solar Energy Engineering, vol. 117, no. 2, pp. 75-84, 1995.

[31] N. Sendhil Kumar and K. S. Reddy, "Numerical investigation of natural convection heat loss in modified cavity receiver for fuzzy focal solar dish concentrator," Solar Energy, vol. 81, no. 7, pp. 846-855, 2007.

[32] M. Prakash, S. B. Kedare, and J. K. Nayak, "Numerical study of natural convection loss from open cavities," International Journal of Thermal Sciences, vol. 51, pp. 23-30, 2012.

[33] H. Sajjadi, M. Gorji, G. H. R. Kefayati, D. D. Ganji, and M. S. $\mathrm{Nia}$, "Simulation of natural convection flow in an inclined open cavity using lattice boltzmann method," World Academy of Science, Engineering and Technology, vol. 79, pp. 265-271, 2011.

[34] A. A. Mohamad, "Natural convection in open cavities and slots," Numerical Heat Transfer A, vol. 27, no. 6, pp. 705-716, 1995.

[35] O. Polat and E. Bilgen, "Laminar natural convection in inclined open shallow cavities," International Journal of Thermal Sciences, vol. 41, no. 4, pp. 360-368, 2002.

[36] Fluent CFD software 6.3.26 version, copyright 2006.

[37] C. P. Kothandaraman and S. Subramanyan, Heat and Mass Transfer Data Book, New Age International Publishers, New Delhi, India, 4th edition, 1998.

[38] S. Kakac, R. K. Shah, and W. Aung, Handbook of Single Phase Convective Heat Transfer, John Wiley and Sons, New York, NY, USA, 1987. 

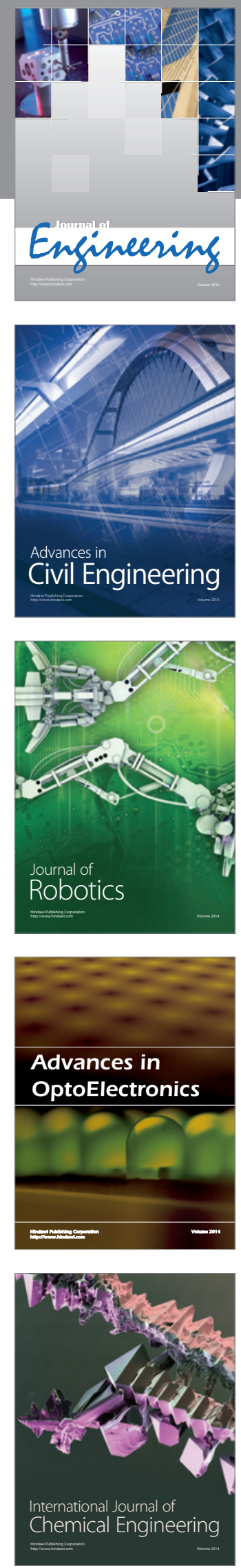

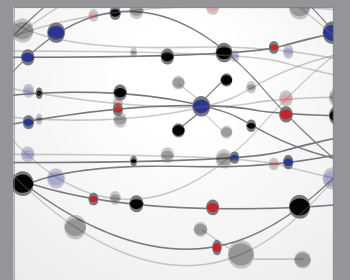

The Scientific World Journal
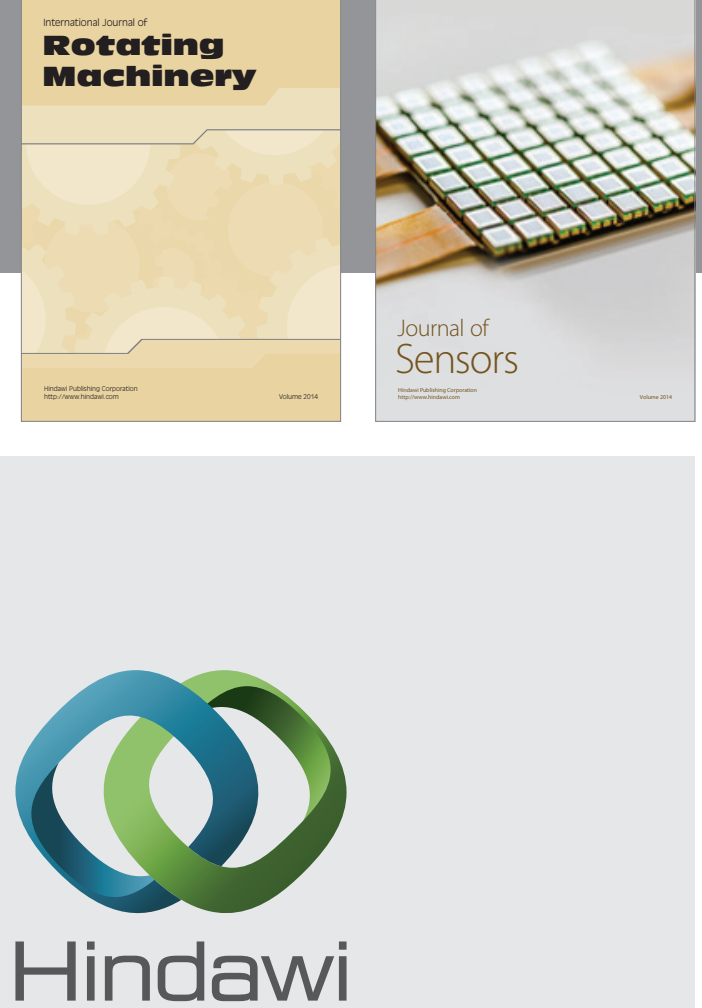

Submit your manuscripts at http://www.hindawi.com
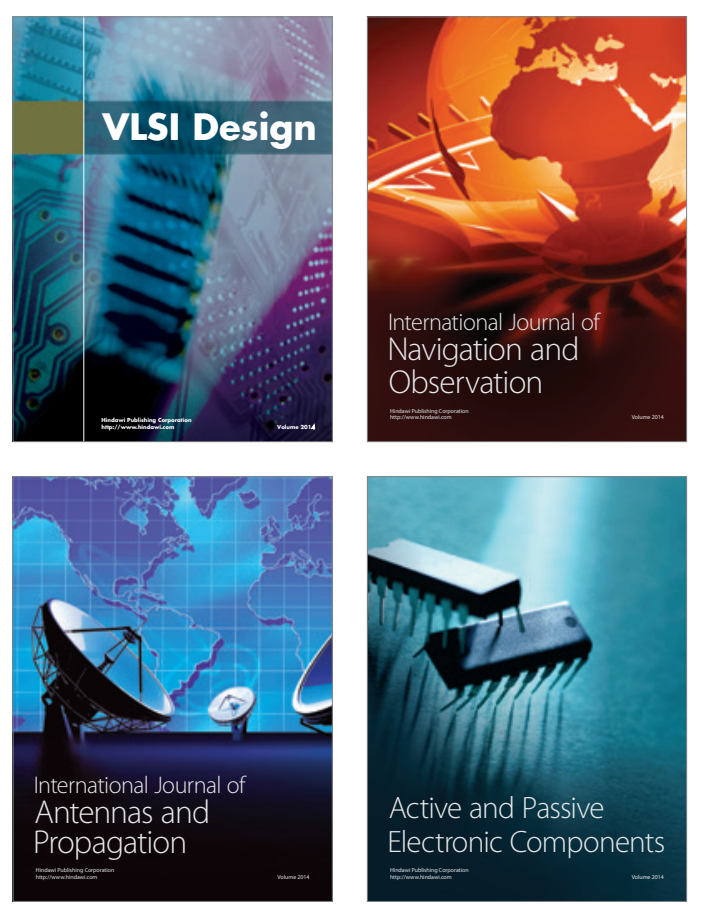
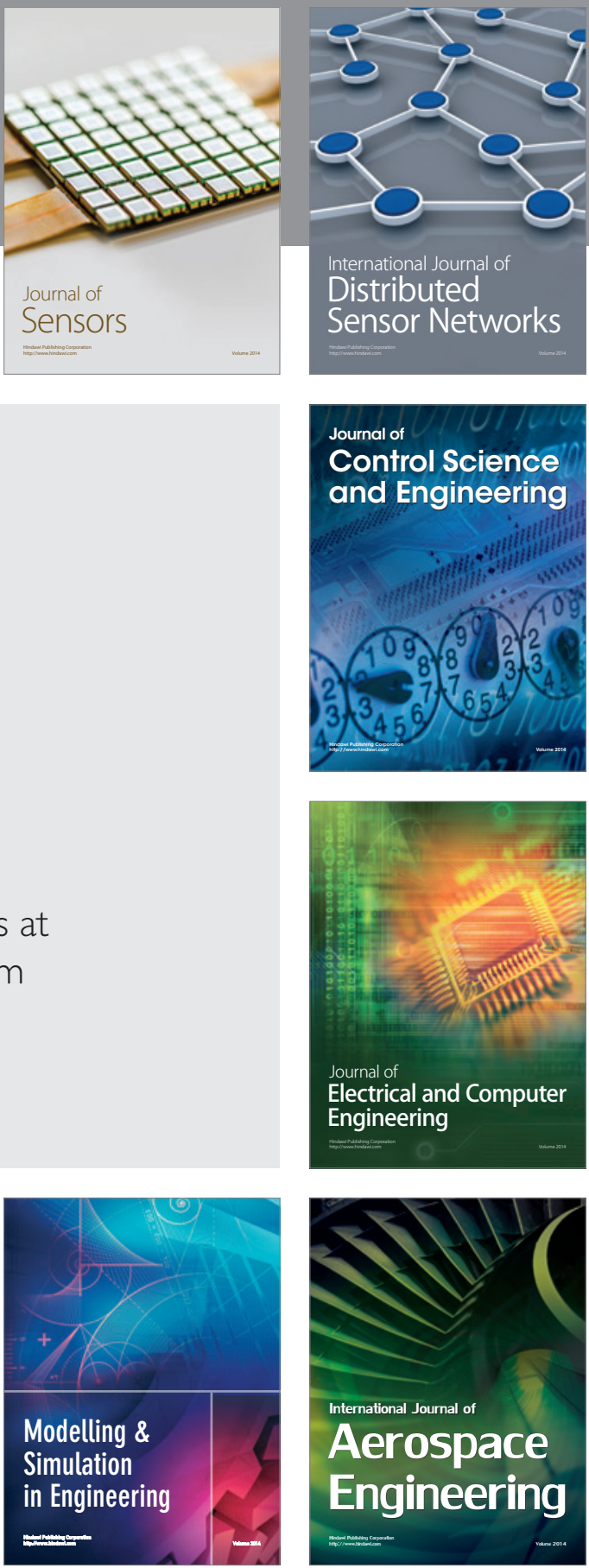

Journal of

Control Science

and Engineering
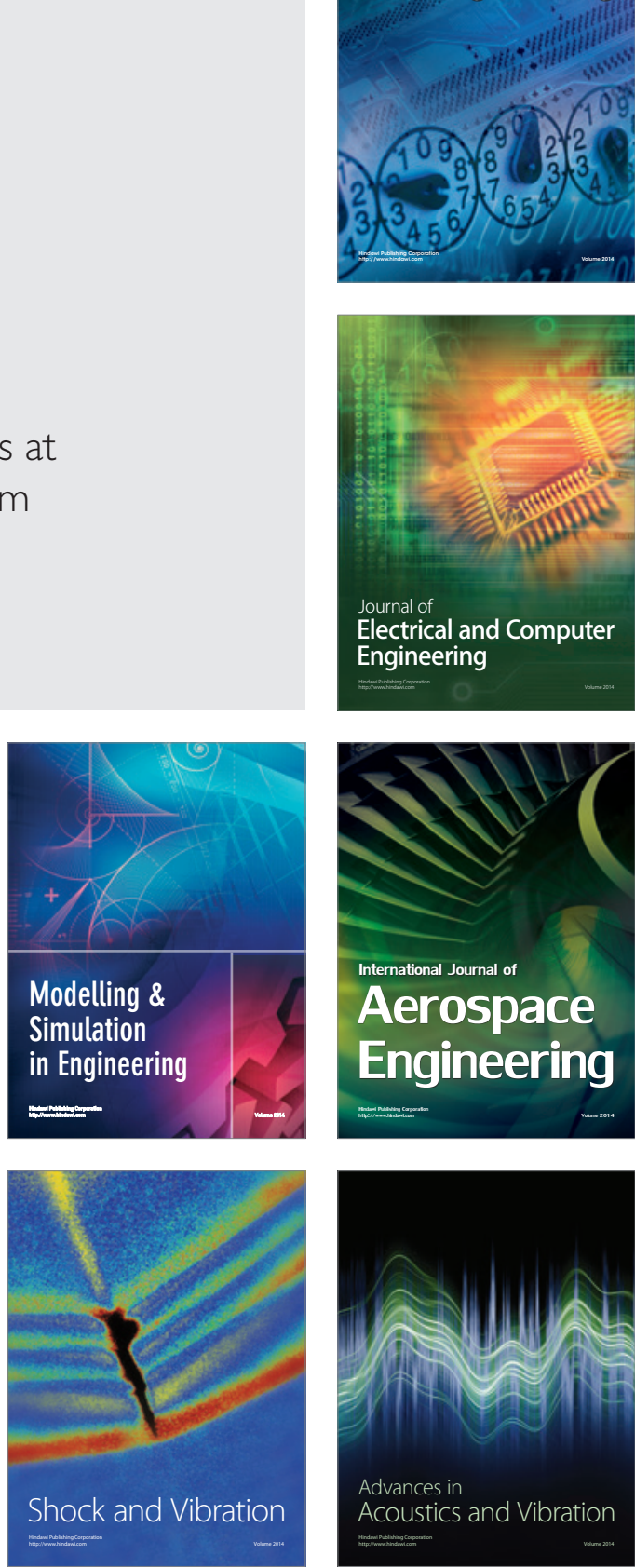